\title{
Ecosystem implications of conserving endemic versus eradicating introduced large herbivores in the Galapagos Archipelago
}

\author{
Guillaume Bastille-Rousseau ${ }^{\text {a,b,* }}$, James P. Gibbs ${ }^{\text {a,b }}$, Karl Campbell ${ }^{\text {c,d }}$, Charles B. Yackulic ${ }^{\text {e }}$, Stephen Blake ${ }^{\text {a,f,g,h,i,j }}$
}

a Department of Environmental and Forest Biology, State University of New York, College of Environmental Science and Forestry, Syracuse, NY 13210, United States

${ }^{\mathrm{b}}$ Roosevelt Wild Life Station, State University of New York, College of Environmental Science and Forestry, Syracuse, NY 13210, United States

c Island Conservation, Puerto Ayora, Galapagos Islands, Ecuador

d School of Geography, Planning E' Environmental Management, The University of Queensland, St Lucia 4072, Australia

e U.S. Geological Survey, Southwest Biological Science Center, Flagstaff, AZ 86001, United States

${ }^{\mathrm{f}}$ Max Planck Institute for Ornithology, Radolfzell, Germany

${ }^{g}$ Whitney Harris World Ecology Center, University of Missouri-St. Louis, St. Louis, MO 63121, United States

h Department of Biology, Washington University, St. Louis, MO 63130, United States

${ }^{i}$ Charles Darwin Foundation, Puerto Ayora, Galapagos, Ecuador

j WildCare Institute, Saint Louis Zoo, 1 Government Drive, Saint Louis, MO 63110, United States

\section{A R T I C L E I N F O}

\section{Article history:}

Received 12 October 2016

Received in revised form 3 January 2017

Accepted 6 February 2017

Available online 10 February 2017

\section{Keywords:}

Feral goats (Capra hircus)

Breakpoint regression

NDVI

Giant tortoise (Chelonoidis)

Satellite remote sensing

Restoration ecology

\begin{abstract}
A B S T R A C T
Restoration of damaged ecosystems through invasive species removal and native species conservation is an increasingly common practice in biodiversity conservation. Estimating the degree of ecosystem response attributable specifically to eradication of exotic herbivores versus restoration of native herbivores is often difficult and is complicated by concurrent temporal changes in other factors, especially climate. We investigated the interactive impacts of native mega-herbivores (giant tortoises) and the eradication of large alien herbivores (goats) on vegetation productivity across the Galapagos Archipelago. We examined archipelago-wide patterns of Normalized Difference Vegetation Index (NDVI) as a proxy for vegetation productivity between 2001 and 2015 and evaluated how goat and historical and current tortoise occurrence influenced productivity. We used a breakpoint analysis to detect change in trends in productivity from five targeted areas following goat eradication. We found a positive association between tortoise occurrence and vegetation productivity and a negative association with goat occurrence. We also documented an increase in plant productivity following goat removal with recovery higher in moister regions than in arid region, potentially indicating an alternate stable state has been created in the latter. Climate variation also contributed to the detected improvement in productivity following goat eradication, sometimes obscuring the effect of eradication but more usually magnifying it by up to $300 \%$. Our work offers perspectives regarding the effectiveness and outcomes of eradicating introduced herbivores and re-introducing native herbivores, and the merits of staging them simultaneously in order to restore critical ecosystem processes such as vegetation productivity.
\end{abstract}

@ 2017 Elsevier Ltd. All rights reserved.

\section{Introduction}

Biodiversity is under serious threat as a result of human activities that include over-exploitation of natural resources, the spread of invasive alien species, and climatic change (Brook et al., 2008). These activities are altering the distribution and abundance of myriad species, communities and ecosystems, often leading to local and global extinction (Clavero et al., 2009) and to the loss of key species interactions (e.g. loss of predators, ecological engineer, seed dispersal, and

\footnotetext{
* Corresponding author at: Department of Environmental and Forest Biology, State University of New York, College of Environmental Science and Forestry, Syracuse, NY 13210, United States.

E-mail address: gbastill@esf.edu (G. Bastille-Rousseau).
}

herbivory; Dirzo et al., 2014; Neuschulz et al., 2016). Such changes have led to profound transformation of ecosystems worldwide, resulting in functional changes in ecological processes, and potential reduction in the maintenance of planetary ecosystem services (Balvanera et al., 2006).

Restoration of ecosystems to their historic state is a recurrent (Swetnam et al., 1999) and often challenging (Hobbs et al., 2006) problem in conservation ecology. Altered ecosystems are frequently resilient to change and often require drastic measures to even partially restore them to their original states (Hobbs et al., 2006). Examples include the complete removal of invasive species and the conservation or reintroduction of keystone species (Hunter et al., 2013). Given the cost involved in restoration measures, efficient monitoring and assessment of their effectiveness is critical to assess the success of current management 
and to inform future restoration efforts (Yoccoz et al., 2001). Yet restoration programs are often conducted without robust monitoring plans and rigorous controls (Block et al., 2001) leading to the majority of restoration programs being poorly documented (Schweizer et al., 2016). It follows that disentangling the contribution of restoration measures from spurious temporal changes in other abiotic factors (e.g. climate) is difficult and can potentially lead to erroneous conclusions regarding the effectiveness of specific management actions.

In the absence of field-based monitoring data to address responses of restoration targets to management, satellite-generated, remotely sensed data may provide useful indicators of ecosystem change in response to large-scale conservation efforts (Pettorelli et al., 2014; see review by Wang et al., 2010), including those that involve herbivores that "engineer" terrestrial vegetation, either through eradication of undesirable, non-native species or restoration of desirable, native species of herbivores. The utility of satellite remote sensing includes repeatable, standardized and large-extent information on trends of numerous ecological indicators. A frequently used indicator of the status of terrestrial vegetation is primary productivity, which reflects critical aspects of ecosystem functioning (McNaughton et al., 1989). Many satellite-based vegetation indices have been shown to relate to primary productivity, among these, the Normalized Difference Vegetation Index (NDVI) is used in the widest variety of applications (Pettorelli et al., 2005). For example, remotely sensed NDVI has been used to show a decrease in productivity following the introduction and spread of a herbivore (Ali and Pelkey, 2013) and an increase in productivity following the eradication of different herbivores (Lohr et al., 2014; Ortíz-Alcaraz et al., 2016), and a decrease in productivity following socio-politically-driven increases in grazing pressure (Sankey et al., 2009).

Here, we study how the historical and current occurrence of a native mega-herbivore and the eradication of large alien herbivores affect vegetation productivity estimated from NDVI across the Galapagos Archipelago. A wide variety of alien, often invasive species have been introduced to the Galapagos Islands over the last several centuries (Carrion et al., 2007; Cruz et al., 2005; Eckhardt, 1972). Among the most destructive alien vertebrates are feral goats, which pose a threat to island biota worldwide because of their important browsing of shrubs and trees (Campbell and Donlan, 2005). On several islands goat abundance has caused declines in vegetative cover and productivity (Desender et al., 2006; Henderson and Dawson, 2009). On Galapagos, the consequences of introduced herbivores such as goats on vegetation had indirect impacts across trophic levels, including populations and communities of terrestrial invertebrates (Desender et al., 1999) and birds (Donlan et al., 2007). Giant tortoises (Chelonoidis spp.) were also affected (Márquez et al., 2013), a concern at both the species and ecosystem levels, because these tortoises are important ecosystem engineers and seed dispersers (Heleno et al., 2011; Blake et al., 2012) that also have measurable consequences on vegetation by trampling and grazing (Gibbs et al., 2008). Moreover, giant tortoise reintroduction on some islands of the Galapagos has been shown to positively affect vegetation diversity and productivity (Gibbs et al., 2010, 2008). On Isabela and Santiago Islands, the intensity of goat impacts on vegetation and resulting ecosystem degradation led conservationists to mount a successful goat eradication project (Carrion et al., 2011), which was later implemented on other Galapagos islands.

Here, we assess the interacting effects of endemic giant tortoises and introduced large herbivores on vegetation productivity in the Galapagos Archipelago. First, we characterize archipelago-wide patterns of NDVI as a proxy for vegetation productivity from 2001 to 2015 and evaluate how the historical and current occurrence of tortoises and large introduced herbivores influence productivity. Based on the "grazing optimization hypothesis" (Milchunas and Lauenroth, 1993), we predicted that both historical and current occurrence of giant tortoises would have a positive effect on vegetation productivity through their roles as herbivores and seed dispersers but that introduced herbivores would reduce productivity. Second, we focus on five sentinel areas where introduced herbivores with different initial densities had been eradicated during the monitoring period. We use breakpoint (piecewise) analyses to detect potential change in trends in productivity estimated from the NDVI time-series following eradication while also controlling for external variation in abiotic factors including topography and climate. We predicted an increase in vegetation productivity following the eradication of introduced herbivores with the magnitude of the increase proportional to initial density of introduced herbivores. Our work offers perspectives regarding the effectiveness of both introduced herbivore eradication and conservation and re-introduction of native herbivores to restore fundamental ecosystem processes.

\section{Methods}

\subsection{Study area}

The Galapagos Archipelago ( $\left.1^{\circ} 40^{\prime \prime} \mathrm{N}-1^{\circ} 36^{\prime \prime} \mathrm{S}, 89^{\circ} 16^{\prime \prime}-92^{\circ} 01^{\prime \prime} \mathrm{W}\right)$ is comprised of 21 volcanic islands and over 100 rocks and islets situated in the eastern Pacific Ocean some $1000 \mathrm{~km}$ west of the Ecuadorian coast (Snell et al., 1996). Our study focused on the 15 largest islands (Fig. 1). Interactions between shifting ocean currents, wind direction and topography create extensive spatiotemporal gradients in temperature, precipitation and, by extension, vegetation (Trueman and D'Ozouville, 2010). The islands are comprised of several vegetation types including, tree-, shrub-, and herb-dominated communities (Trueman and D'Ozouville, 2010). Lava fields and other barren areas are also found on most islands while agricultural areas are present at intermediate elevations on islands with permanent human settlement (Isabela, Santa Cruz, Floreana and San Cristobal, with the exception of Baltra).

\subsection{Spatial data}

To quantify spatio-temporal change in vegetation productivity, we used the MODIS (Moderate Resolution Imaging Spectroradiometer) NDVI product. The MOD13Q1 data product was retrieved from the online Data Pool, courtesy of the NASA Land Processes Distributed Active Archive Center (LP DAAC), US Geological Survey/Earth Resources Observation and Science (EROS) Center, Sioux Falls, South Dakota, https:// lpdaac.usgs.gov/data_access/data_pool. NDVI has been shown to reliably capture variation in vegetation growth, productivity, and resources available to herbivores (Pettorelli et al., 2005). MODIS vegetation indices, which span the years 2000-2015, are provided at $250 \mathrm{~m}$ by $250 \mathrm{~m}$ resolution every 16 days, yielding 23 composites per year.

To correct for NDVI errors induced by clouds and other sources, we performed iterative interpolation data reconstruction following Julien and Sobrino (2010). This approach was deemed more appropriate than a parametric fit, such as the double logistic approach (e.g. see Hird and McDermid, 2009), given that we did not have strong a priori expectations for seasonal and symmetrical variation in vegetation development in some areas. Most of our analyses were focused on productivity in three vegetation categories (trees, shrubs and herbs) that herbivores could impact. Clirsen (2006) delineated these land cover types using unsupervised classification of a series of SPOT and Landsat imageries. We also used a digital elevation model (DEM) of the archipelago to generate raster layers of elevation, slope and aspect.

\subsection{Distribution and abundance of giant tortoises and introduced large herbivores}

Before humans discovered the Galapagos Islands in 1535, tortoises were likely present on ten different islands (Caccone et al., 2002, Table 1; MacFarland et al., 1974). Today, tortoises occur on just six islands (Table 1). Areas occupied currently and historically by giant tortoises were delineated through participatory mapping by 30 experts familiar with tortoise populations. Their knowledge was captured during an international planning workshop held in 2012 (see Supplementary 


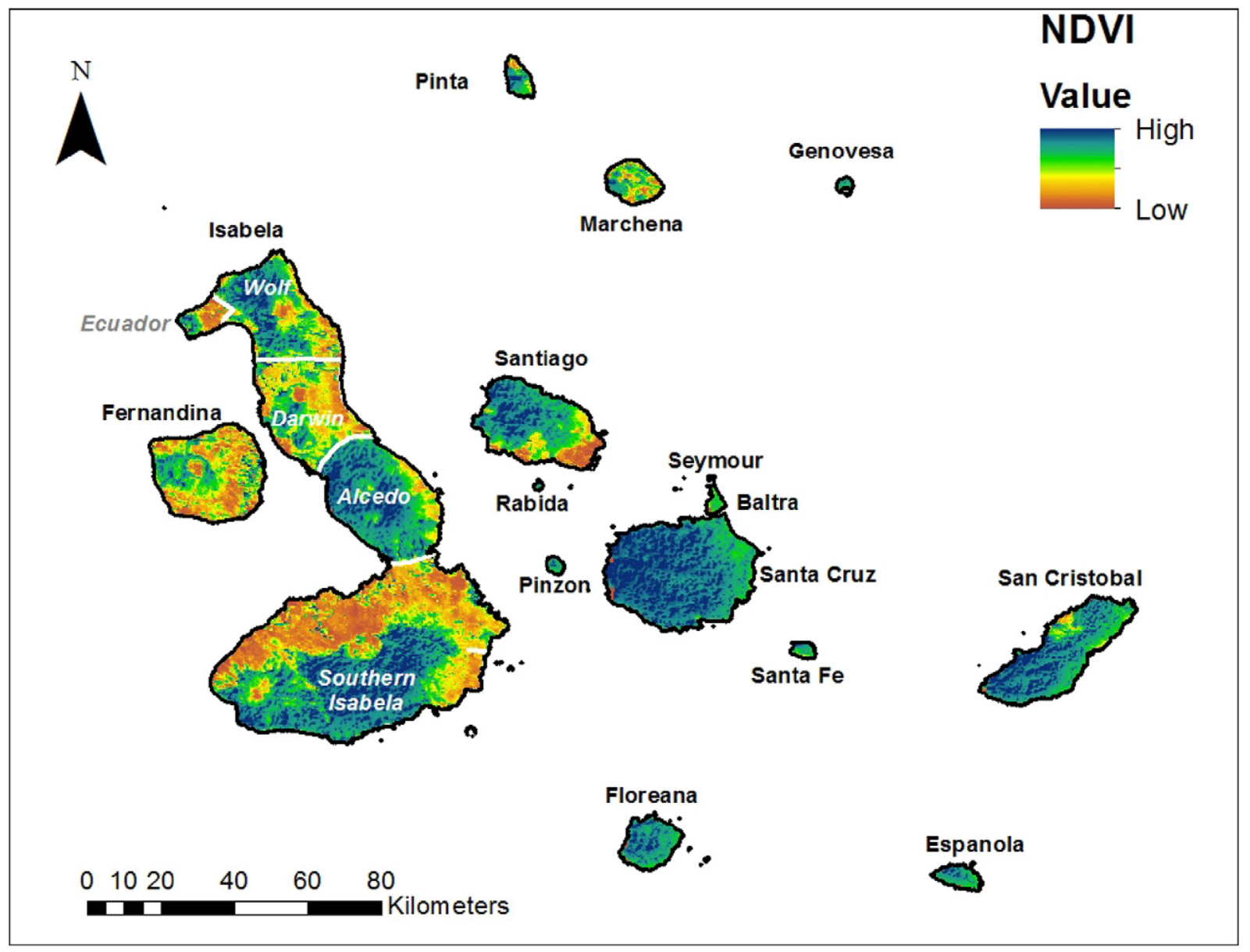

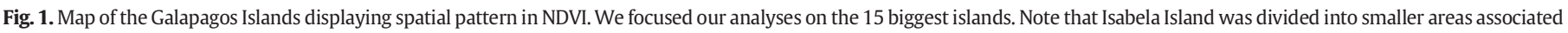
with individual volcanoes (names in white) to better account for spatial and temporal change in goat density.

Table 1

Distribution and abundance of giant tortoises and introduced large herbivores (goat, donkey and cattle) on 15 islands in the Galapagos Archipelago. Range in abundance of introduced herbivore was provided for 2001-2015 when MODIS satellite data were available. See also Fig. 1.

\begin{tabular}{llllll}
\hline Island & $\begin{array}{l}\text { Area } \\
\left(\mathrm{km}^{2}\right)\end{array}$ & $\begin{array}{l}\text { Tortoise } \\
\text { current } \\
\text { density } \\
\left(\text { ind } / \mathrm{km}^{2}\right)\end{array}$ & $\begin{array}{l}\text { Tortoise } \\
\text { historical } \\
\text { occurrence }\end{array}$ & $\begin{array}{l}\text { Introduced } \\
\text { herbivores } \\
\text { density } \\
\left(\text { ind } / \mathrm{km}^{2}\right)\end{array}$ & $\begin{array}{l}\text { \% of goat at } \\
\text { maximum } \\
\text { density }\end{array}$ \\
\hline Baltra & 25.3 & 0 & No & $0-2.5$ & 100 \\
Espanola & 60.9 & 14.1 & Yes & 0 & 0 \\
Fernandina & 644.8 & 0 & No & 0 & 0 \\
Floreana & 172.7 & 0 & Yes & $0-11.2$ & \\
Genovesa & 13.8 & 0 & No & 0 & 0 \\
Isabela & & & Yes & $0-51.6$ & 99.8 \\
$\quad$ Alcedo & 792.6 & 8.0 & No & $0-0.04$ & 100 \\
Ecuador & 100.1 & 0 & Yes & $0-10.3$ & 100 \\
Darwin & 639.6 & 1.3 & Yes & $0.002-1.2$ & 66.5 \\
South Isabela & 2649.9 & 1.2 & Yes & $0-11.3$ & 100 \\
$\quad$ Wolf & 636.0 & 9.4 & No & $0-0.04$ & 100 \\
Marchena & 131.4 & 0 & Yes & $0-0.03$ & 100 \\
Pinta & 59.47 & 0 & Yes & 0 & 0 \\
Pinzon & 17.97 & 29.6 & No & 0 & 0 \\
Rabida & 4.95 & 0 & Yes & $0.43-12.1$ & 96.3 \\
San Cristobal & 559.48 & 3.3 & Yes & $0.53-2.3$ & 88.9 \\
Santa Cruz & 983.93 & 3.6 & Yes & 0 & 0 \\
Santa Fe & 24.50 & 0 & Yes & $0-156.1$ & 99.9 \\
Santiago & 575.22 & 2.0 & No & 0 & 0 \\
Seymour & 1.91 & 0 & & & 0 \\
\hline
\end{tabular}

material, Fig. S1 and S2 for a depiction of the historical and current tortoise distribution). For occupied zones, we estimated current tortoise density for each island based on published literature. We summarize information relative to the distribution and abundance of tortoises and introduced herbivores in Table 1.

We estimated an annual time series of density of introduced large herbivores (goats, donkeys and cattle) on each island based on published literature (Campbell et al., 2004; Carrion et al., 2011; Cruz et al., $2009,2006)$. Donkey and cattle numbers were extremely low in comparison to those of goats, so we assumed that any detected effects of introduced herbivores on vegetation originated predominantly due to goats (Table 1). For Isabela Island, we used spatial data from the actual removal effort (ground and aerial hunting) to estimate introduced herbivore density for each volcano for the northern part of the island while we consider the southern section of the island with two adjacent volcanoes as a single zone (Fig. 1).

\subsection{Statistical analyses}

2.4.1. Archipelago-wide analysis of herbivore impact on vegetation while controlling for environmental co-variates

We first estimated the relationship between the mean NDVI value of a $250 \mathrm{~m} \times 250 \mathrm{~m}$ pixel on a given year as a function of abiotic and biotic variables. We performed the analysis separately for pixels in each land cover type (herb, shrub and tree). Abiotic variables included elevation, slope and aspect (dummy coded variables with eastern aspect being the reference level, and northern, southern and western being the other levels) found at the center of the pixel. We considered three biotic 
variables: 1) whether the pixel was historically occupied by tortoises, 2) whether it was currently occupied by tortoises, and 3) whether the pixel was currently occupied by introduced herbivores. We also considered two-way interactions between historic and current tortoise occupancy and current occupancy by tortoises and introduced herbivores (Table 2). Given that some areas had extremely low densities of introduced herbivores, we tested different cut-offs to consider an area as occupied by introduced herbivores $(0.5,1,5$ and 10 introduced herbivores $/ \mathrm{km}^{2}$ ). Akaike Information Criteria (AIC; Burnham and Anderson, 2002) was used to select the best combination of biotic variables including the best cut-off for introduced herbivore occupancy. In all instances, $\triangle \mathrm{AIC}$ was $>10$ between the top and second model, so we present results only from the top-ranked model. We performed the analysis using a linear mixed effect model with two independent random effects: pixel and year nested within island. These random effects allowed us to estimate unaccounted variation attributable to these factors. The random effect associated to pixel is particularly useful given the resolution of our data as it allows each pixel to have its own NDVI signature and therefore account for variation in species composition and other elements that may influence local NDVI values. We also scaled and centered continuous variables to improve comparability of regression coefficients (Schielzeth, 2010). We verified for multicollinearity in our top model using the variance inflation factor (Graham, 2003). Models were fitted using the package lme4 in R v.3.2.3 using maximum likelihood when comparing fixed effects and then using restricted maximum likelihood for final estimation of model parameters (Zuur et al., 2009). We estimated a marginal and conditional $\mathrm{R}^{2}$ (Nakagawa and Schielzeth, 2013) for the top model as well as the marginal $\mathrm{R}^{2}$ for the model excluding all biotic variables. We did not include a spatial correlation structure in the models because the residuals of the top models where not spatially autocorrelated ( $\mathrm{R}<0.1$ for spatial lags 1 to 30 pixels).

We then repeated the above analysis but used other NDVI statistics rather than mean annual NDVI: the maximum annual NDVI, the minimum annual NDVI, the mean of the five highest annual NDVI values, the annual amplitude, the annual coefficient of variation, and the maximum annual rate of change estimated between two composites. Results for these analyses are presented in Supplementary material, Table S1.

\subsubsection{Effect of island-specific introduced herbivore eradication programs on} vegetation

To evaluate the impact of the removal of introduced herbivores on vegetation productivity, we performed a finer scale analysis of five areas before and after introduced herbivores had been removed: Santiago Island, Floreana Island, and three volcanoes on northern Isabela Island (Alcedo, Darwin, and Wolf, Fig. 1). Only Floreana Island does not currently host giant tortoises (Table 1). These areas varied in terms of habitat structure and the initial density of introduced herbivores in 2000 at the beginning of the MODIS NDVI monitoring period. Initial density was ca. 10 introduced herbivores $/ \mathrm{km}^{2}$ for Floreana Island, and Darwin and Wolf volcanoes, ca. 50 introduced herbivores $/ \mathrm{km}^{2}$ on Alcedo Volcano and ca. 150 introduced herbivores $/ \mathrm{km}^{2}$ on Santiago Island (Carrion et al., 2011). Between 2002 and 2006 introduced herbivores were removed from these areas (Carrion et al., 2011) with most of the removal happening in 2003 and 2004 for Santiago and the second half of 2004 for Alcedo, Darwin and Wolf Volcanoes. Removal occurred between 2006 and 2009 on Floreana Island. Based on "known" eradication events we tested whether the removal of introduced herbivores led to a change in vegetation trends for land cover type in each area. To do so, we fitted a piecewise generalized least square (GLS) regression to detect a continuous change in trend in time-series of mean annual NDVI values averaged for each land cover type and area. We used GLS to account for temporal autocorrelation by adding a first-order auto-regressive correlation matrix (AR1; Zuur et al., 2009). We compared the piecewise regression with an intercept only GLS and compared the two models based on likelihood ratio-test (LRT). We compared differences between detected breaks and expected breaks associated with introduced herbivore eradication. These analyses were conducted using the package "nlme" in R v.3.2.3.

In order to robustly evaluate whether estimated breaks in time-series were the consequence of spurious annual variation or goat removal we first developed a permutation exercise which tested the probability of observing a smaller or equal delay between the expected break based on eradication for each area and the detected break based on the intrinsic variability present in each time series. For a time-series from a given area and land cover type, we randomly resampled with replacement

Table 2

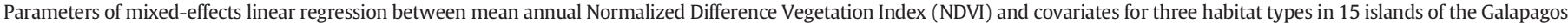

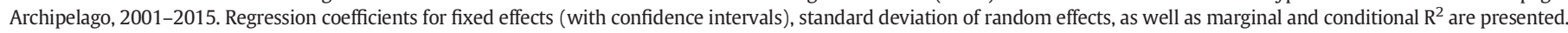

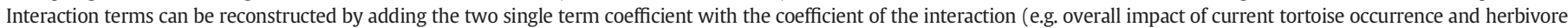
occurrence on productivity in herb cover type is: $0.1172-0.0262-0.0091=0.0819$ ). Results for other annual statistics are presented in Table S1, Supplementary material.

\begin{tabular}{|c|c|c|c|}
\hline Parameters & Herb & Shrub & Tree \\
\hline \multicolumn{4}{|l|}{ Fixed effects } \\
\hline Intercept & $0.3631(0.3216,0.4036)$ & $0.3968(0.3605,0.4328)$ & $0.4223(0.3732,0.4714)$ \\
\hline Elevation & $0.0614(0.0588,0.0639)$ & $0.1098(0.1059,0.1137)$ & $0.1162(0.114,0.1184)$ \\
\hline Elevation $^{2}$ & $-0.0236(-0.0245,-0.0226)$ & $-0.0225(-0.0239,-0.0211)$ & $-0.0323(-0.0331,-0.0315)$ \\
\hline Slope & $0.013(0.0107,0.0153)$ & $0.0131(0.0105,0.0158)$ & $0.0092(0.0073,0.0111)$ \\
\hline Slope $^{2}$ & $0.0009(0.0002,0.0016)$ & $-0.0068(-0.0077,-0.006)$ & $0.0003(-0.0004,0.0011)$ \\
\hline North & $-0.026(-0.0298,-0.0223)$ & $-0.022(-0.0254,-0.0186)$ & $-0.0315(-0.0343,-0.0288)$ \\
\hline South & $0.0628(0.0592,0.0664)$ & $0.0301(0.0268,0.0334)$ & $0.0554(0.0528,0.058)$ \\
\hline West & $0.0312(0.0272,0.0352)$ & $-0.003(-0.0071,0.0011)$ & $0.0105(0.0078,0.0133)$ \\
\hline Tortoise historical & $0.109(0.1047,0.1134)$ & $0.1554(0.1514,0.1593)$ & $0.1426(0.1393,0.1459)$ \\
\hline Tortoise current & $0.1172(0.1016,0.1328)$ & $0.2543(0.1595,0.349)$ & $0.2053(0.1462,0.2644)$ \\
\hline Tortoise historical: current & $-0.0555(-0.0714,-0.0396)$ & $-0.1925(-0.2872,-0.0976)$ & $-0.1362(-0.1953,-0.077)$ \\
\hline Introduced herbivore presence & $-0.0262(-0.0466,-0.0054)$ & $-0.0401(-0.0597,-0.0203)$ & $-0.0197(-0.0427,0.0033)$ \\
\hline Tortoise current: introduced herbivore presence & $-0.0091(-0.0098,-0.0084)$ & $0.0067(0.0052,0.0082)$ & $0.0034(0.0022,0.0045)$ \\
\hline Introduced herbivore cut-off $\left(\mathrm{x} / \mathrm{km}^{2}\right)$ & 0.5 & 1 & 10 \\
\hline \multicolumn{4}{|l|}{ Random effects $(\sigma)$} \\
\hline Pixel ID & $0.1027(0.1018,0.1036)$ & $0.0941(0.0932,0.095)$ & $0.0895(0.0889,0.0901)$ \\
\hline Island: year & $0.0508(0.0462,0.0558)$ & $0.0491(0.045,0.0536)$ & $0.0462(0.042,0.0509)$ \\
\hline Island & $0.0814(0.0567,0.1166)$ & $0.0736(0.052,0.1046)$ & $0.093(0.0645,0.1355)$ \\
\hline Residuals & $0.0416(0.0415,0.0417)$ & $0.041(0.0409,0.0411)$ & $0.0419(0.0419,0.042)$ \\
\hline \multicolumn{4}{|l|}{$\mathrm{R}^{2}$} \\
\hline Marginal $\mathrm{R}^{2}$ abiotic model & 0.2909 & 0.2775 & 0.1510 \\
\hline Marginal $\mathrm{R}^{2}$ biotic model & 0.4165 & 0.3781 & 0.2743 \\
\hline Conditional $\mathrm{R}^{2}$ biotic model & 0.9500 & 0.9430 & 0.9416 \\
\hline
\end{tabular}


each time-series 10,000 times. For each of the simulated time-series, we fitted the piecewise GLS regression and an intercept-only GLS and estimated the breakpoints. We compared the percentage of the simulations that had a smaller estimated lag between the observed and expected break point than the values estimated from the analysis of the actual data. We assert that the percentage estimated from this permutation exercise represents the probability of observing the detected break by chance given variability in our data. We considered the detected break as significant when $p$-values for the LRT was $>0.05$ and $<5 \%$ of permutations had smaller estimated lag. We also identified "potential" breaks in trend when $<10 \%$ of permutations had smaller estimated lags than the estimated lag.

\subsubsection{Disentangling the impact of herbivores versus background annual variability of environmental factors on vegetation productivity \\ Annual variation in temperature and precipitation is likely to have} an important role in vegetation productivity and could drive multi-annual trends in NDVI time-series (Fig. S3). Such patterns could potentially facilitate vegetation recovery following eradication, or alternatively, suppress vegetation recovery. To estimate the contribution of external environmental annual factors (e.g. precipitation) on yearly NDVI, we reran the global mixed model explained above on the subset of islands without introduced herbivores and tortoise (Table 1) keeping the same random effect structure (pixel and year nested within island). We averaged the yearly random intercepts for each year and subtracted the among years average to these values. This difference indicated if a given year was more productive (positive values) or less productive (negative) than average based on external elements not accounted for in our models. Indeed, for each land cover type, these values correlated strongly with average annual precipitation received in the Galapagos (all R $>0.78$, Fig. S6).

In order to disentangle the contribution of environmental variability and the removal of introduced herbivores, we performed the piecewise regression analysis explained above using time-series of NDVI values that were adjusted to account for the annual trend previously estimated. We performed the same permutation exercise on the "detrended" timeseries and compared outputs with results from the original time-series to assess the strength of potentially confounding influences of introduced herbivore eradication and annual environmental variation. We compared the results from this second analysis to estimate the gain in vegetation attributable due to the eradication of introduced herbivores versus to annual variability.

\section{Results}

\subsection{Impacts of abiotic and biotic variables on vegetation productivity}

The impacts of abiotic and biotic variables on annual mean productivity was similar among land cover types (Table 2). Higher productivity was observed at intermediate elevation for each land cover and on steeper slopes for tree and herb cover (Table 2 and Fig. S3). Aspect also influenced productivity: relative to productivity observed in east oriented zones, south and west facing zones had higher productivity (except for shrub cover) whereas north orientation had lower productivity (Table 2). Introduced herbivore presence decreased productivity, although the impact was detected at different introduced herbivore densities for each land cover (Table 2). Areas historically occupied by tortoises had higher productivity while areas occupied currently had even higher values (Table 2). Areas in herbaceous cover occupied by both tortoises and introduced herbivores had somewhat lower productivity while shrub and tree land cover exhibited a small increase in productivity (Table 2 ).

Overall, adding variables related to occurrence of introduced herbivores and tortoises considerably improved model fit, increasing marginal $\mathrm{R}^{2}$ by $>0.1$ for each land cover type (Table 2 ). Nevertheless, adding random effects (pixel ID and year nested within island) drastically improved the model with conditional $\mathrm{R}^{2}>0.90$ for each land cover type. Random variance was higher among pixels and among islands (Table 2), indicating that most of the unaccounted variation in our data was attributable to pixel and island. Random intercepts at the island level indicated inconsistent patterns in productivity across land cover types; some islands generally displayed higher productivity for specific land cover relative to other islands, but also displayed lower productivity for some habitat (Fig. S3). Annual patterns in productivity were similar among habitat types (Fig. S5).

\subsection{The effect of eradication of introduced herbivores}

Compared to an intercept-only model, a piecewise regression with one continuous break fit significantly better to the time-series for most land cover types and area when using raw time-series. The only exception was Floreana Island where the intercept-only model provided better fit (Table S2 and Fig. 2). For most time-series, breaks were estimated between 2004 and 2006 and indicated an increase in vegetation productivity after the break was detected (Table S2 and Fig. 2). The permutation exercise indicated that a significant break following the eradication of introduced herbivores was detected on Alcedo Volcano for each plant community type (herbaceous, shrubs and trees) and also on Darwin Volcano for the shrub communities. All plant community types on Santiago Island, herbaceous zones on Darwin Volcano and shrub and tree zones on Wolf Volcano also potentially displayed a positive increase in vegetation productivity following the start of their respective introduced herbivore eradication programs. When the effect of annual environmental factors such as precipitation was accounted for, fewer time-series displayed increases in productivity following the removal of introduced herbivores (Table S3 and Fig. 3). All land cover types on Alcedo Volcano as well as herb and shrub plant community types on Darwin Volcano displayed a positive increase after introduced herbivores were removed, whereas herb and tree plant community types on Wolf Volcano also potentially increased following introduced herbivore removal. The magnitude of the increase in productivity following the removal of introduced herbivores was also not related to their initial density. Taken altogether, these trends indicate that the removal of introduced herbivores explained the majority of the increase in productivity for herbaceous land cover but a small portion of the detected increase for shrub and tree land covers (Fig. 4).

\section{Discussion}

We quantify the interacting impacts of environmental factors, native mega-herbivores and introduced large herbivores on vegetation productivity. As expected, we observed increased productivity associated with the occurrence of native mega-herbivores, giant Galapagos tortoises, while the occurrence of introduced herbivores had the opposite effect. Accordingly, we documented an increase in productivity following the removal of introduced herbivores, but with variation in the magnitude of recovery among areas and land cover types. Importantly, multi-annual variation in climate also contributed to the detected increase in productivity following eradication, obscuring the effect of eradication in some instances and magnifying it in others. In this regard, our work provides an analytical framework and a set of considerations to rigorously quantify the contribution of the eradication of invasive species on vegetation characteristics when using satellite remote sensing data.

Historical tortoise occurrence was associated with areas of higher productivity while currently occupied areas have even higher productivity (Table 2). Overall, current tortoise occurrence is associated with an increase in vegetation productivity of ca. $20 \%$. Given the structure of our data, it is difficult to tease apart whether the positive association between current tortoise occurrence and vegetation productivity is due to tortoise "engineering" of their habitat, if they are selecting for areas of higher productivity, or whether the effect is a combination of the two. 

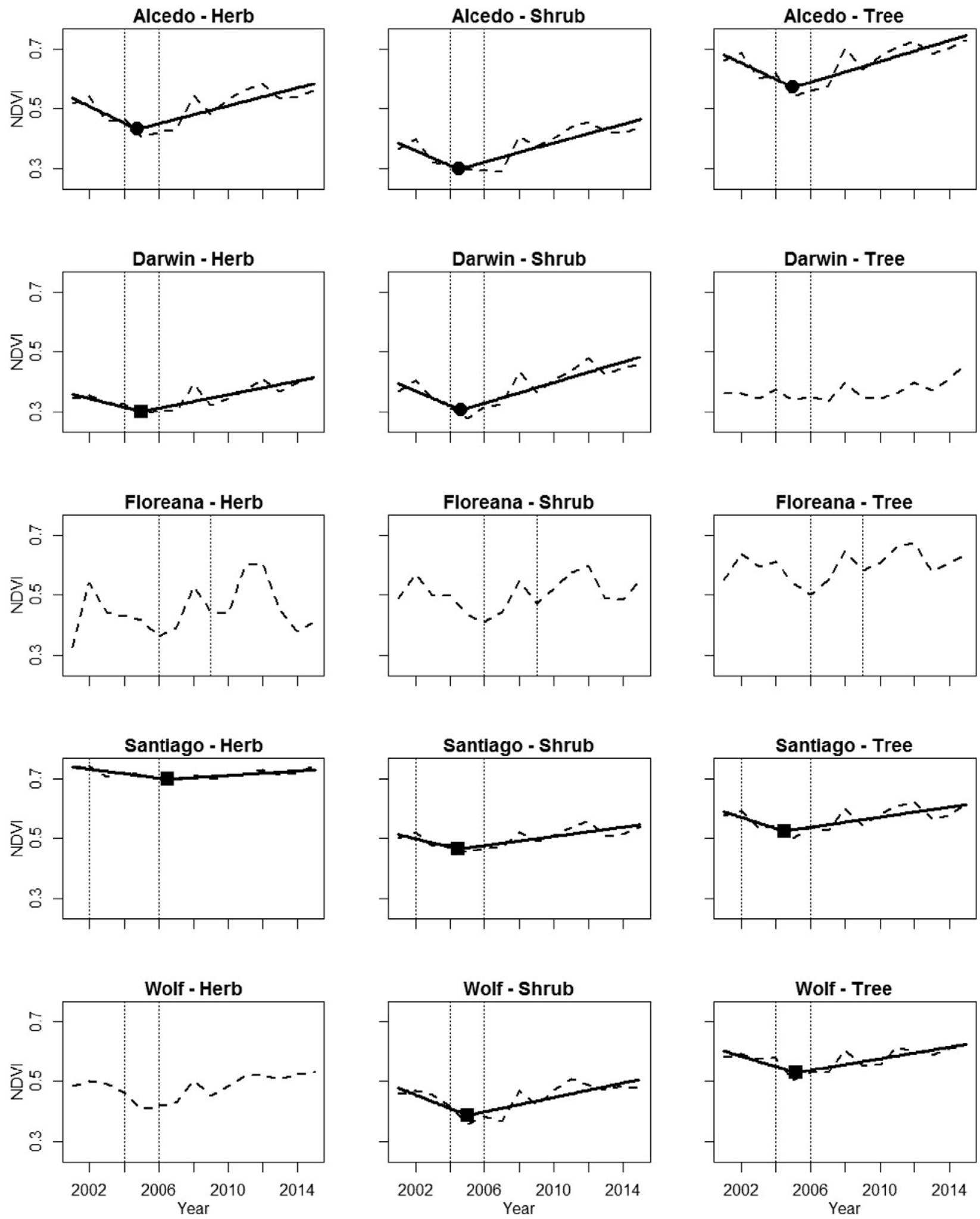

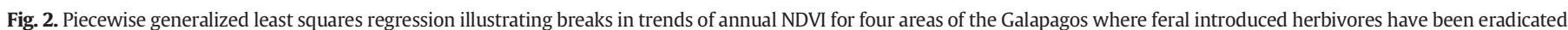

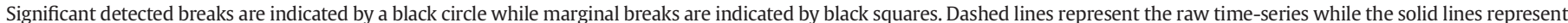
the detected trends. Vertical lines indicate years during which eradication happened.

Tortoise abundance data were only available at the island level and because robust census data are unavailable were of questionable quality, thus it is difficult to integrate tortoise density within our global analysis without having this variable confounded by an island effect. Previous analyses of movement data from tortoises fitted with GPS telemetry units indicate that tortoises are able to track changes in vegetation productivity and select greener areas at a fine scale (Bastille-Rousseau, in press; Yackulic et al., in review; Blake et al., 2013). However, these analyses also showed that tortoises favor vegetation quality over quantity, thus they are not always found in the most productive areas. Tortoises 

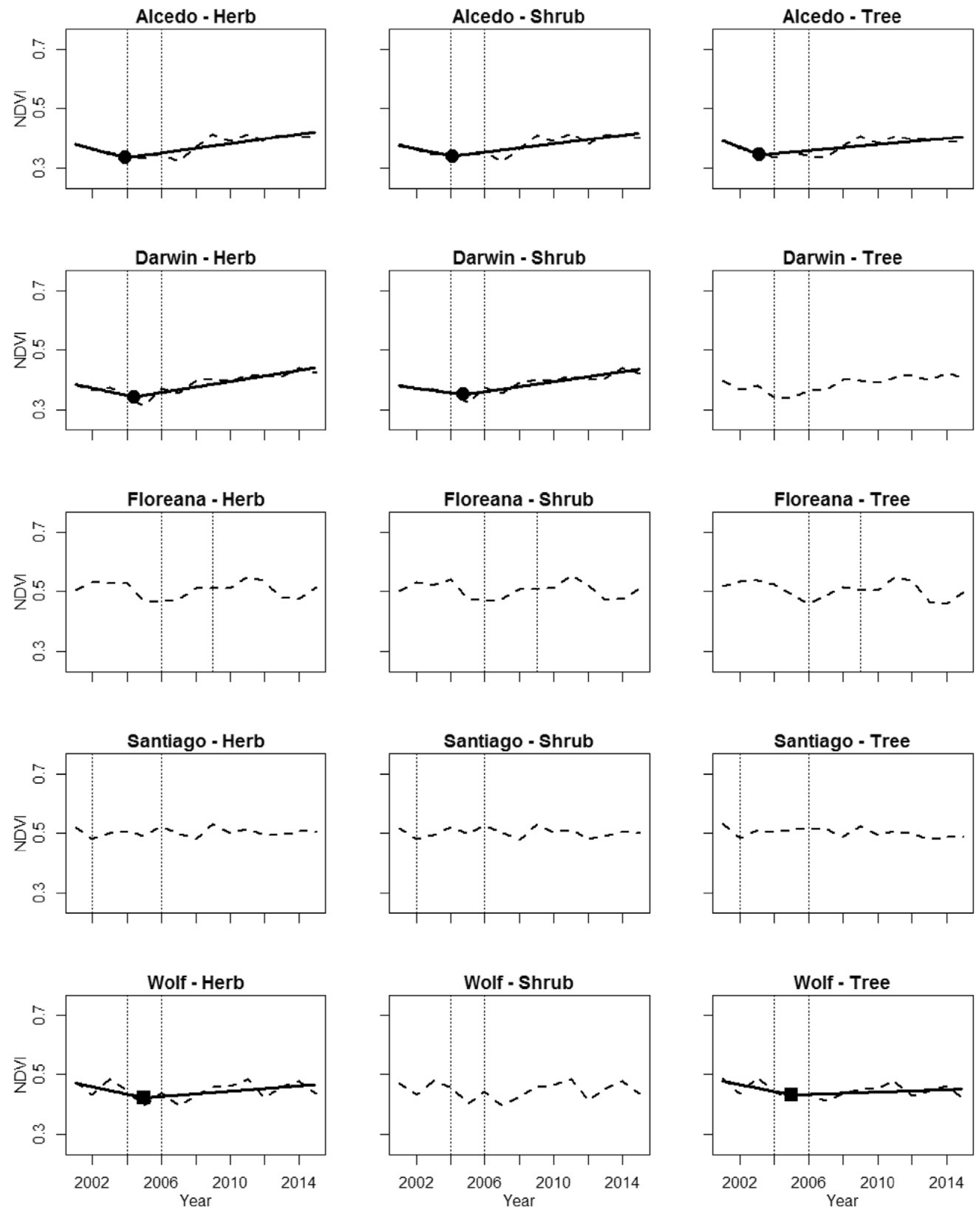

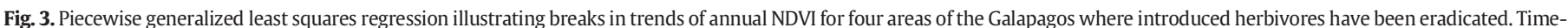

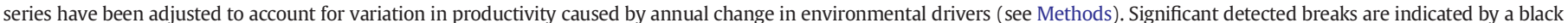

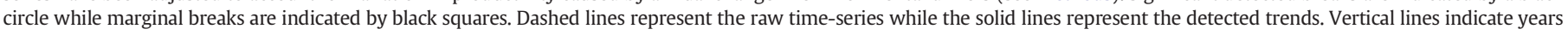
during which eradication occurred.

may enhance vegetation productivity, especially through mechanical impacts on the vegetation of the herbaceous layer and breaking down woody plants while moving; possibly maintaining grassland associations through foraging. Notably, increases in tortoise density on Aldabra
Atoll improves the productivity of grassland areas (Hnatiuk, 1978; Merton et al., 1976) often leading to the development of high diversity grazing lawns as observed for many grazing ecosystem systems around the world (Johnson and Matchett, 2001; McNaughton, 1984). These 


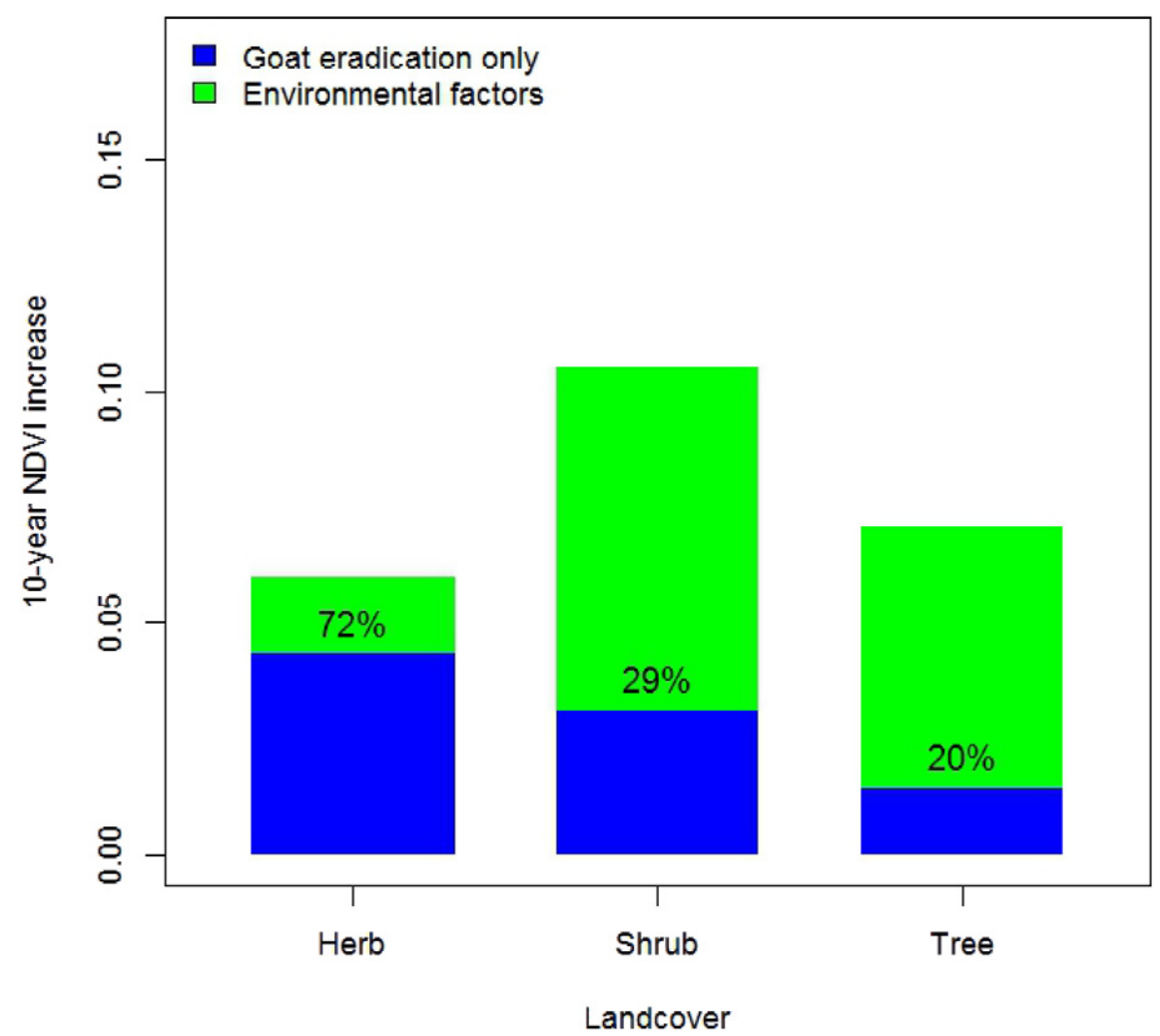

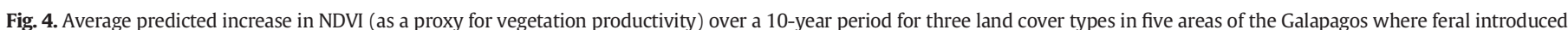

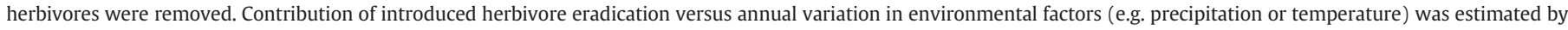

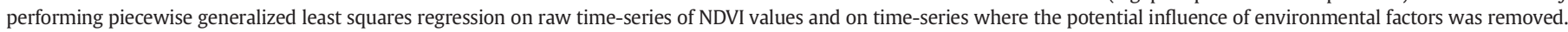
Percent contribution of the removal of introduced herbivores to total vegetation gain is also provided (see Methods for partitioning variance).

studies support the notion that Galapagos tortoises are "gardeners of the Galapagos" not only via their role as seed dispersers but also by stimulating vegetation productivity. However, further research is needed to better understand the different mechanisms associated with goat- and tortoise-induced changes on plant productivity.

Our results illustrate that not all herbivores are "cut from the same cloth". In our study, native herbivore-giant tortoises-enhanced plant productivity whereas the introduced herbivore-goats-did the opposite. The effects may have been amplified in Galapagos, as it would be in many island systems, because most native island vegetation has not evolved with such herbivores as goats and the modes and mechanisms by which they forage. Interestingly, we detected different thresholds of sensitivity in the density at which land covers were susceptible to introduced herbivores. Herbaceous areas were the most sensitive to herbivore impact while tree areas were the least. Nevertheless, the impact of introduced herbivores appeared relatively modest with decreases in NDVI ranging from 2 to $4 \%$ depending of land cover types (Table 2). Previous findings both in Galapagos (Desender et al., 2006; Henderson and Dawson, 2009) and elsewhere (Campbell and Donlan, 2005; Lohr et al., 2014) suggest a sharper reduction in productivity occurred in response to introduced herbivores. Our archipelago-wide study was based on coarse-grained mean density estimates of introduced herbivores in occupied areas ranging from 15 to 28 herbivores $/ \mathrm{km}^{2}$ which failed to map the full range of abundances [in some areas and times $>50-150$ herbivores $/ \mathrm{km}^{2}$ (Table 1)]. Thus we captured the global overall effect of introduced herbivores, but did not illustrate their localized and often devastating impacts (Brewington, 2013) at smaller spatio-temporal scales.

By analyzing archipelago-wide pattern in productivity contrasting where and when introduced herbivores were present, we were able to isolate the contribution of the removal of introduced herbivores on change in productivity (Fig. 4). The climate of Galapagos is known for its multi-annual climatic events, including El Niño and La Niña cycles that bring respectively more and less annual precipitation (Trueman and D'Ozouville, 2010). Failure to consider precipitation in our analysis would have led to overestimation of the impact of the removal of introduced herbivores, especially for shrub and tree land cover types (Fig. 4). Based on our four focal areas, we predict the eradication of introduced herbivores resulted in a $5 \%$ gain in vegetation productivity over a 10 year period in herbaceous species land cover with smaller gains among other vegetation types. Contrary to our expectation, we did not a find a relationship between the magnitude of the increase in productivity following the removal of introduced herbivores and their initial density. Most interesting is the fact that when accounting for annual variation in external factors, the island with the highest goat density (Santiago Island) failed to show any productivity increase. We also observed no sign of increased productivity on Floreana Island. In comparison to the three focal areas on Isabela Island, Santiago and Floreana Islands do not possess high elevation areas and both receive less annual precipitation than other islands (Snell et al., 1996). The degree of devastation was particularly high on these islands, owing to a longer time which introduced herbivores have been present, which combined with greater aridity ultimately may have affected capacity to recover (resilience) at the relatively short time periods observed. Whether the outcome of these interactions is an alternate stable state requiring further intervention in the form of direct vegetation management is a more complex question depending on a time series of vegetation cover that extends earlier than the MODIS time series available for this analysis. Caution is also required as NDVI fluctuations may hide changes in species communities, including replacement of native species by invasive species (Walsh et al., 2008). This can be important given that goats are expected to slowly transform community to woody plants while tortoises can assist in the dispersal of invasive species. Ground truthing of observations or finer-scale remote sensing 
products would be required if monitoring of changes in species composition within plant communities is a central goal.

The absence of reversal in vegetation productivity on Santiago and Floreana Islands following eradication also raises the question of the desirability of coupling invasive herbivore eradication with tortoise restoration in an archipelago where tortoises-the only large native herbivore-remain at $<10 \%$ of their original abundance (Marquez et al., 2004). Simulations based on data from Pinta Island where tortoises have been recently introduced illustrated that an expanding tortoise population would ultimately cause a reduction in woody vegetation but over a very long timescale (Hunter and Gibbs, 2014). On Espanola Island, where the reintroduction of tortoises began 40 years ago, the current impact of tortoise is limited to a small fraction of the island where woody plants do not block tortoise movement, yet woody plant density is greatly reduced in areas of high movement, e.g., near Opuntia cactus trees (Gibbs et al., 2014, 2010, 2008). In other words, vegetation recovery patterns could be substantially different with invasive herbivore removal in the absence of significant tortoise densities (which characterizes the situation over much of Galapagos today). An important question then is whether eradication of invasive herbivores requires restoring giant tortoise populations to their historic densities in order for plant communities and vegetation dynamics to be returned to their likely original state.

\section{Conclusion}

Satellite remote sensing has become a useful tool for ecological studies with wide-ranging applications, especially given the temporal and spatial availability of these data (Kerr and Ostrovsky, 2003; Pettorelli et al., 2014). We took advantage of the large-extent and multi-annual availability of these products in combination with well-documented, large-scale management interventions to investigate patterns in productivity across the Galapagos Archipelago. Given increasing awareness in optimizing monetary costs and effectiveness associated to conservation efforts, satellite remote sensing products offer a retrospective and rigorous ways of evaluating specific measures.

\section{Acknowledgments}

This project was supported by the National Science Foundation (DEB 1258062). GBR was also supported by a postdoctoral fellowship from the Fonds de recherche Québec Nature et Technologies. We thank L.-P. Rousseau for help in processing the satellite data. Any use of trade, product, or firm names is for descriptive purposes only and does not imply endorsement by the U.S. Government.

\section{References}

Ali, R., Pelkey, N., 2013. Satellite images indicate vegetation degradation due to invasive herbivores in the Andaman Islands. Curr. Sci. 105, 209-214.

Balvanera, P., Pfisterer, A.B., Buchmann, N., He, J.-S., Nakashizuka, T., Raffaelli, D., Schmid, B., 2006. Quantifying the evidence for biodiversity effects on ecosystem functioning and services. Ecol. Lett. 9:1146-1156. http://dx.doi.org/10.1111/j.1461-0248.2006. 00963.x.

Bastille-Rousseau, G., Gibbs, J.P., Yackulic, C.B., Frair, J.L., Cabrera, F., Rousseau, L.-P., Wikelski, M., Kümmeth, F., Blake, S., in press. Animal movement in the absence of predation: environmental drivers of movement strategies in giant Galapagos tortoises. Oikos doi: 10.1111/oik.03928.

Blake, S., Wikelski, M., Cabrera, F., et al., 2012. Seed dispersal by Galápagos tortoises. J. Biogeogr. 39:1961-1972. http://dx.doi.org/10.1111/j.1365-2699.2011.02672.x.

Blake, S., Yackulic, C.B., Cabrera, F., Tapia, W., Gibbs, J.P., Kümmeth, F., Wikelski, M., 2013. Vegetation dynamics drive segregation by body size in Galapagos tortoises migrating across altitudinal gradients. J. Anim. Ecol. 82:310-321. http://dx.doi.org/10.1111/ 1365-2656.12020.
Block, W.M., Franklin, A.B., Ward, J.P., Ganey, J.L., White, G.C., 2001. Design and implementation of monitoring studies to evaluate the success of ecological restoration on wildlife. Restor. Ecol. 9, 293-303.

Brewington, L., 2013. Mapping invasion and eradication of feral goats in the Alcedo region of Isabela Island, Galapagos. Int. J. Remote Sens. 34:2286-2300. http://dx.doi.org/10. 1080/01431161.2012.743695.

Brook, B.W., Sodhi, N.S., Bradshaw, C.J.A., 2008. Synergies among extinction drivers under global change. Trends Ecol. Evol. 23:453-460. http://dx.doi.org/10.1016/j.tree.2008. 03.011 .

Burnham, K.P., Anderson, D.R., 2002. Model selection and multimodel inference. Springer, New York, USA.

Caccone, A., Gentile, G., Gibbs, J.P., Frirts, T.H., Snell, H.L., Betts, J., Powell, J.R., 2002. Phylogeography and history of giant Galápagos tortoises. Evolution 56:2052-2066 N. Y. 10.1111/j.0014-3820.2002.tb00131.x.

Campbell, K., Donlan, C.J., 2005. Feral goat eradications on islands. Conserv. Biol. 19: 1362-1374. http://dx.doi.org/10.1111/j.1523-1739.2005.00228.x.

Campbell, K., Donlan, C.J., Cruz, F., Carrion, V., 2004. Eradication of feral goats Capra hircus from Pinta Island, Galápagos, Ecuador. Oryx 38:328-333. http://dx.doi.org/10.1017/ S0030605304000572.

Carrion, V., Donlan, C.J., Campbell, K., Lavoie, C., Cruz, F., 2007. Feral donkey (Equus asinus) eradications in the Galapagos. Biodivers. Conserv. 16, 437-445.

Carrion, V., Donlan, C.J., Campbell, K.J., Lavoie, C., Cruz, F., 2011. Archipelago-wide island restoration in the Galápagos Islands: reducing costs of invasive mammal eradication programs and reinvasion risk. PLoS One 6, e18835. http://dx.doi.org/10.1371/journal. pone.0018835.

Clavero, M., Brotons, L., Pons, P., Sol, D., 2009. Prominent role of invasive species in avian biodiversity loss. Biol. Conserv. 142:2043-2049. http://dx.doi.org/10.1016/j.biocon. 2009.03.034.

CLIRSEN, 2006. Cartografía Galápagos 2006: Conservación en otra Dimensión.

Cruz, F., Josh Donlan, C., Campbell, K., Carrion, V., 2005. Conservation action in the Galapagos: Feral pig (Sus scrofa) eradication from Santiago Island. Biol. Conserv. 121, 473-478.

Cruz, F., Harcourt, S., Lavoie, C., Campbell, K., Carrion, V., Donlan, J., Isabela, P., Jiménez, D., Snell, H., Larrea, C., Roy, D., Wedin, M., Wollocombe, R., Tate, J., Harcourt, S., Lutz, E., Lutz, T., 2006. Atlas of Project Isabela. Biol. Conserv.

Cruz, F Carrion, V Campbell, KJ Lavoie, C Donlan, CJ 2009. Bio-economics of largescale eradication of feral goats from Santiago Island, Galapagos. J. Wildl. Manag. 73: 191-200. http://dx.doi.org/10.2193/2007-551.

Desender, K., Baert, L., Maelfait, J., Verdyck, P., 1999. Conservation on Volcan Alcedo (Galapagos): terrestrial invertebrates and the impact of introduced feral goats. Biol. Conserv. 87.

Desender, K., Baert, L., Maelfait, J.-P., Verdyck, P., 2006. Effects of the feral goat population explosion on Alcedo Volcano (Isabela, Galapagos) between 1986 and 1996. Galapagos Res. 1999, 2-7.

Dirzo, R., Young, H.S., Galetti, M., Ceballos, G., Isaac, N.J.B., Collen, B., 2014. Defaunation in the Anthropocene. Science 345 (80-)

Donlan, C.J., Campbell, K., Cabrera, W., Lavoie, C., Carrion, V., Cruz, F., 2007. Recovery of the Galápagos rail (Laterallus spilonotus) following the removal of invasive mammals. Biol. Conserv. 138, 520-524.

Eckhardt, R.C., 1972. Introduced plants and animals in the Galápagos Islands. Bioscience 22:585-590. http://dx.doi.org/10.2307/1296204.

Gibbs, J.P., Hunter, E.A., Shoemaker, K.T., Tapia, W.H., Cayot, L.J., 2014. Demographic outcomes and ecosystem implications of giant tortoise reintroduction to española island, Galapagos. PLoS One 9, e110742. http://dx.doi.org/10.1371/journal.pone.0110742.

Gibbs, J.P., Marquez, C., Sterling, E.J., 2008. The role of endangered species reintroduction in ecosystem restoration: tortoise-cactus interactions on Espanola Island, Galapagos. Restor. Ecol. 16:88-93. http://dx.doi.org/10.1111/j.1526-100X.2007.00265.x.

Gibbs, J.P., Sterling, E.J., Zabala, F.J., 2010. Giant tortoises as ecological engineers: a longterm quasi-experiment in the Galapagos Islands. Biotropica 42:208-214. http://dx. doi.org/10.1111/j.1744-7429.2009.00552.x.

Graham, M.H., 2003. Confronting multicollinearity in ecological multiple regression. Ecology $84,2809-2815$.

Heleno, R., Blake, S., Jaramillo, P., 2011. Frugivory and seed dispersal in the Galápagos: what is the state of the art? Integr. Comp. Biol. 6:110-126. http://dx.doi.org/10. 1111/j.1749-4877.2011.00236.x.

Henderson, S., Dawson, T.P., 2009. Alien invasions from space observations: detecting feral goat impacts on Isla Isabela, Galapagos Islands with the AVHRR. Int. J. Remote Sens. 30:423-433. http://dx.doi.org/10.1080/01431160802339472.

Hird, J.N., McDermid, G.J., 2009. Noise reduction of NDVI time series: an empirical comparison of selected techniques. Remote Sens. Environ. 113:248-258. http://dx.doi. org/10.1016/j.rse.2008.09.003.

Hnatiuk, S.H., 1978. Plant dispersal by the Aldabran giant tortoise, Geochelone gigantea (Schweigger). Oecologia 36:345-350. http://dx.doi.org/10.1007/BF00348060.

Hobbs, R.J., Arico, S., Aronson, J., Baron, J.S., Bridgewater, P., Cramer, V.A., Epstein, P.R., Ewel, J.J., Klink, C.A., Lugo, A.E., Norton, D., Ojima, D., Richardson, D.M., Sanderson, E.W., Valladares, F., Vilà, M., Zamora, R., Zobel, M., 2006. Novel ecosystems: theoretical and management aspects of the new ecological world order. Glob. Ecol. Biogeogr. $15,1-7$.

Hunter, E.A., Gibbs, J.P., 2014. Densities of ecological replacement herbivores required to restore plant communities: a case study of giant tortoises on Pinta Island, Galapagos. Restor. Ecol. 22:248-256. http://dx.doi.org/10.1111/Rec.12055.

Hunter, E.A., Gibbs, J.P., Cayot, L.J., Tapia, W., 2013. Equivalency of Galápagos giant tortoises used as ecological replacement species to restore ecosystem functions. Conserv. Biol. 27:701-709. http://dx.doi.org/10.1111/cobi.12038.

Johnson, L.C., Matchett, J.R., 2001. Fire and grazing regulate belowground processes in tallgrass prairie. Ecology 82, 3377-3389. 
Julien, Y., Sobrino, J.a., 2010. Comparison of cloud-reconstruction methods for time series of composite NDVI data. Remote Sens. Environ. 114:618-625. http://dx.doi.org/10. 1016/j.rse.2009.11.001.

Kerr, J.T., Ostrovsky, M., 2003. From space to species: ecological applications for remote sensing. Trends Ecol. Evol. 18:299-305. http://dx.doi.org/10.1016/s01695347(03)00071-5.

Lohr, C., Van Dongen, R., Huntley, B., Gibson, L., Morris, K., 2014. Remotely monitoring change in vegetation cover on the Montebello Islands, Western Australia, in response to introduced rodent eradication. PLoS One 9:1-14. http://dx.doi.org/10.1371/ journal.pone.0114095.

MacFarland, C.G., Villa, J., Toro, B., 1974. The Galapagos giant tortoises (Geochelone elephantopus) part II: conservation methods. Biol. Conserv. 6, 198-212.

Marquez, C., Wiedenfeld, D., Snell, H., Fritts, T., Belen, M.F., MacFarland, C., Tapia, W., Naranjo, S., 2004. Estado actual de las poblaciones de tortugas terrestres gigantes (Geochelone spp., Chelonia: testudinae) en las islas Galápagos. Ecol. Apl. 3, 98-111.

Márquez, C., Gibbs, J.P., Carrión, V., Naranjo, S., Llerena, A., 2013. Population response of giant Galápagos tortoises to feral goat removal. Restor. Ecol. 21:181-185. http://dx. doi.org/10.1111/j.1526-100X.2012.00891.X.

McNaughton, S.J., 1984. Grazing lawns: animals in herds, plant form and coevolution. Am. Nat. $124,863-886$.

McNaughton, S.J., Oesterheld, M., Frank, D.A., Williams, K.J., 1989. Ecosystem-level patterns of primary productivity and herbivory in terrestrial habitats. Nature 341: 142-144. http://dx.doi.org/10.1038/341142a0.

Merton, L.F.H., Bourn, D.M., Hnatiuk, R.J., 1976. Giant tortoise and vegetation interactions on aldabra atoll-part 1: inland. Biol. Conserv. 9:293-304. http://dx.doi.org/10.1016/ 0006-3207(76)90051-3.

Milchunas, D.G., Lauenroth, W.K., 1993. Quantitative effects of grazing on vegetation and soils over a global range of environments. Ecol. Monogr. 63, 327-366.

Nakagawa, S., Schielzeth, H., 2013. A general and simple method for obtaining R2 from generalized linear mixed-effects models. Methods Ecol. Evol. 4:133-142. http://dx. doi.org/10.1111/j.2041-210x.2012.00261.x.

Neuschulz, E.L., Mueller, T., Schleuning, M., Böhning-Gaese, K., 2016. Pollination and seed dispersal are the most threatened processes of plant regeneration. Sci. Rep. 6, 29839.

Ortíz-Alcaraz, A., Maya-Delgado, Y., Cortés-Calva, P., Aguirre-Muñoz, A., Rojas-Mayoral, E., Cordoba-Matson, M., Ortega-Rubio, A., 2016. Recovery of vegetation cover and soil after the removal of sheep in Socorro Island, Mexico. Forests 7:91. http://dx.doi.org/ 10.3390/f7040091.
Pettorelli, N., Vik, J.O., Mysterud, A., Gaillard, J.M., Tucker, C.J., Stenseth, N.C., 2005. Using the satellite-derived NDVI to assess ecological responses to environmental change. Trends Ecol. Evol. 20:503-510. http://dx.doi.org/10.1016/j.tree.2005.05.011.

Pettorelli, N., Safi, K., Turner, W., 2014. Satellite remote sensing, biodiversity research and conservation of the future. Philos. Trans. R. Soc. B 369:20130190. http://dx.doi.org/10. 1098/rstb.2013.0190.

Sankey, T.T., Sankey, J.B., Weber, K.T., Montagne, C., 2009. Geospatial assessment of grazing regime shifts and sociopolitical changes in a mongolian rangeland. Rangel. Ecol. Manag. 62:522-530. http://dx.doi.org/10.2111/.1/REM-D-09-00014.1.

Schielzeth, H., 2010. Simple means to improve the interpretability of regression coefficients. Methods Ecol. Evol. 1:103-113. http://dx.doi.org/10.1111/j.2041-210X.2010. 00012.x.

Schweizer, D., Jones, H.P., Holmes, N.D., 2016. Literature review and meta-analysis of vegetation responses to goat and European rabbit eradications on islands. Pac. Sci. 70 : 55-71. http://dx.doi.org/10.2984/70.1.5.

Snell, H.M., Stone, P.a., Howard, L.S., 1996. A summary of geographical characteristics of the Galapagos Islands. J. Biogeogr. 23:619-624. http://dx.doi.org/10.1111/j.13652699.1996.tb00022.x.

Swetnam, T.W., Allen, C.D., Betancourt, J.L., 1999. Applied historical ecology: using the past to manage for the future. Ecol. Appl. 9, 1189-1206.

Trueman, M., D'Ozouville, N., 2010. Characterizing the Galapagos terrestrial climate in the face of global climate change. Galapagos Res. 67, 26-37.

Walsh, S.J., McCleary, A.L., Mena, C.F., Shao, Y., Tuttle, J.P., González, A., Atkinson, R., 2008. QuickBird and Hyperion data analysis of an invasive plant species in the Galapagos Islands of Ecuador: implications for control and land use management. Remote Sens. Environ. 112:1927-1941. http://dx.doi.org/10.1016/j.rse.2007.06.028.

Wang, K., Franklin, S.E., Guo, X., Cattet, M., 2010. Remote sensing of ecology, biodiversity and conservation: a review from the perspective of remote sensing specialists. Sensors 10:9647-9667. http://dx.doi.org/10.3390/s101109647.

Yackulic, C.B., Blake, S., Bastille-Rousseau, G., n.d. Benefits of the destinations, not costs of the journeys, shape partial migration patterns in Galapagos tortoises. J. Anim. Ecol. (in review).

Yoccoz, N.G., Nichols, J.D., Boulinier, T., 2001. Monitoring of biological diversity in space and time. Trends Ecol. Evol. 16:446-453. http://dx.doi.org/10.1016/S01695347(01)02205-4.

Zuur, A.F., Ieno, E.N., Walker, N.J., Saveliev, A.A., Smith, G.M., 2009. Mixed Effects Models and Extensions in Ecology with R. Springer, New York. 